13,03

\title{
Десорбция атомов калия, стимулированная электронным облучением системы $\mathrm{K} / \mathrm{K}_{x} \mathrm{Au}_{y}$
}

\author{
(C) Ю.А. Кузнецов, М.Н. Лапушкин
}

Физико-технический институт им. А.Ф. Иофрфе РАН,

Санкт-Петербург, Россия

E-mail: Lapushkin@ms.ioffe.ru

Поступила в Редакцию 18 июня 2020 г.

В окончательной редакции 18 июня 2020 г.

Принята к публикации 24 июня 2020 г.

Обнаружена электронно-стимулированная десорбция (ЭСД) атомов К из слоя калия на поверхности $\mathrm{K}_{x} \mathrm{Au}_{y}$. Слой $\mathrm{K}_{x} \mathrm{Au}_{y}$ создавался на подложке вольфрама с нанесенной на нее пленкой золота, толщиной не более пяти атомных слоев. Обнаружена квазирезонансная зависимость выхода ЭСД атомов К от энергии возбуждающих электронов. Квазирезонансная зависимость обусловлена возбуждением остовных уровней $\mathrm{Au} 5 p_{3 / 2}$ и $\mathrm{Au} 5 p_{1 / 2}$. Предложена модель ЭСД атомов $\mathrm{K}$ в системе $\mathrm{K} / \mathrm{K}_{x} \mathrm{Au} y$, адекватно описывающая процессы, протекающие при ЭСД атомов К. Показано, что процессы возбуждения ЭСД атомов К происходят в интерфейсе $\mathrm{K} / \mathrm{K}_{x} \mathrm{Au}_{y}$.

Ключевые слова: электронно-стимулированная десорбция, калий, золото, интерметаллиды.

DOI: 10.21883/FTT.2020.11.50075.130

\section{1. Введение}

Интерметаллиды золото-щелочной металл (ЩМ) известны еще с середины прошлого века [1]. Соединение из двух металлов, являющихся хорошими проводниками, могут образовывать полупроводниковые соединения с большой шириной запрещенной зоны $\sim 2.7 \mathrm{eV}[1,2]$. В интерметаллических соединениях золота со щелочными металлами Аи является анионом [3], а не катионом, как в абсолютном большинстве соединений золота. В настоящее время возрастает интерес к исследованиям различных химических реакций на поверхности золота, о чем свидетельствуют многочисленные публикации подобной химии в журналах. Это стало возможным благодаря прогрессу в квантово-механических расчетах, позволяющему предсказывать и понимать процессы, происходящие на поверхности золота. С другой стороны, наблюдается существенный рост исследований процессов, протекающих на поверхности золота с наночастицами Au. B последние годы наночастицы золота применяются на практике в самых различных областях — от катализа $[4,5]$ и медицины $[6,7]$ до создания различных сенсоров и датчиков [8,9]. Следует отметить, что свойства наночастиц золота зависят не только от их размеров, но и от способа их приготовления. С другой стороны, термическая стабильность у наночастиц золота намного меньше, чем у массивного золота, поэтому важно увеличивать их рабочую температуру.

Калий является промотером многих химических реакций, и поэтому адсорбция атомов $\mathrm{K}$ на поверхность массивного $\mathrm{Au}$ или же на наночастицах $\mathrm{Au}$ может приводить к новым интересным эффектам, таким как увеличение скорости реакций. Скорость реакции окис- ления СО с калием на золоте в несколько раз выше, чем на поверхности золотой пленки на $\mathrm{TiO}_{2}$ [10]. Покрытие калием золотой поверхности увеличивает и адсорбционную способность поверхности по отношению к чистой поверхности золота [11]. Ожидать, что наличие калия на поверхности всегда будет давать положительный эффект не стоит. Так в [12] было показано, что наличие калия на поверхности $\mathrm{TiO}_{2}(110)$ приводит к уменьшению размеров наночастиц золота в полтора раза, однако отжиг при температуре до $700 \mathrm{~K}$ влечет за собой увеличение размеров наночастиц, в отличие от бескалиевой поверхности. Показано, что в системе $\mathrm{Au} / \mathrm{K}-\mathrm{SiO}_{2}$ окисление $\mathrm{CO}$ может происходить при существенно более низких температурах, чем в $\mathrm{Au} / \mathrm{SiO}_{2}$, а для $\mathrm{Au} / \mathrm{TiO}_{2}$ и $\mathrm{Au} / \mathrm{K}-\mathrm{TiO}_{2}$ такого эффекта не наблюдается [5].

Исследованиям адсорбции атомов $\mathrm{K}$ на Аu посвящено множество работ, причем особенно хорошо исследована адсорбция в домонослойном режиме, например, в [13-16]. Однако, как известно [17-20], при напылении покрытия щелочного металла больше, чем в один монослой, или при высокотемпературной адсорбции, происходит формирование полупроводниковых интерметаллических соединений.

Ранее было показано, что интерметаллиды $\mathrm{Na}$ и Cs с золотом являются широкозонными полупроводниками, например, [1,2,17-19]. Однако работ по исследованию интерметаллических полупроводниковых соединений калия с золотом нам известно немного [21,22]. Адсорбция $\mathrm{K}$ на $\mathrm{Au}$ при $T=750 \mathrm{~K}$ формирует на поверхности золотой подложки соединения $\mathrm{K}_{x} \mathrm{Au}_{y}$ и приводит к слету положительных ионов $\mathrm{K}_{2} \mathrm{Au}$ [21]. Из анализа фазовой диаграммы [23] следует ожидать образование при этой температуре соединения $\mathrm{KAu}_{4}$. При $T=300 \mathrm{~K}$ 
образуются следующие соединения: $\mathrm{K}_{2} \mathrm{Au}, \mathrm{KAu}, \mathrm{KAu}_{2}$ и $\mathrm{KAu}_{4}$ - в зависимости от соотношения количества атомов К и $\mathrm{Au}[23]$.

Процесс формирования интерметаллида щелочной металл-золото при низких температурах происходит по следующей схеме: при покрытиях ЩМ меньше одного монослоя формирование интерметаллида не происходит. Напыление же покрытия ЩМ больше одного монослоя приводит к диффузии атомов ЩМ в глубь подложки и формированию интерметаллида. Чем больше напылено ЩМ, тем более толстый слой интерметаллида получается. Следует отметить, что напыление ЩМ на ультратонкую пленку золота толщиной в несколько монослоев имеет следующую особенность: ближайший к W слой $\mathrm{Au}$ не принимает участия в формировании интерметаллида [24].

В [19] изучалось влияние на ЩМ/ЩМАu/Au/W облучения ее поверхности электронами с энергией $E_{e}$ с помощью метода электронно-стимулированной десорбции (ЭСД). Оказалось, что с поверхностей систем $\mathrm{Na} / \mathrm{NaAu} / \mathrm{Au} / \mathrm{W}$ [25] и $\mathrm{Cs} / \mathrm{CsAu} / \mathrm{Au} / \mathrm{W}$ [19] наблюдается ЭСД нейтральных атомов $\mathrm{Na}$ и $\mathrm{Cs}$, соответственно. При этом ЭСД атомов ЩМ появляется лишь после начала образования интерметаллида ЩМ-Аu под верхним монослоем атомов $\mathrm{Na}$ или Cs.

Наличие полупроводниковой или диэлектрической подложки для наблюдения ЭСД можно объяснить тем, что время жизни возбужденного состояния связи адатом-поверхность было достаточно велико как для разрыва этой связи, так и для удаления частицы от поверхности [26,27]. На поверхности металла время жизни возбужденного состояния связи адатом-поверхность мало, так как возбуждение очень быстро гасится за счет ухода возбужденного электрона в зону проводимости, и потому ЭСД на металлах отсутствует. Слой полупроводника (диэлектрика) на поверхности металла существенно увеличивает время жизни возбуждения, и выход ЭСД тогда наблюдается.

Целью настоящей работы было обнаружить и детально изучить электронно-стимулированную десорбцию атомов калия с $\mathrm{K}_{x} \mathrm{Au}_{y}$. Из анализа экспериментальных данных предложить модель ЭСД атомов К в этой системе.

\section{2. Экспериментальная техника}

Напыление пленок $\mathrm{K}$ и $\mathrm{Au}$ на поверхность W(100) ленты из атомарно-чистых источников производилось in situ в сверхвысоковакуумной установке „Спектрометр ЭСД“ при давлении не хуже, чем $5 \cdot 10^{-10}$ Torr при $T=300 \mathrm{~K}$. В качестве подложки исследуемых образцов использовались текстурированные W(100) ленты, очищавшиеся прогревом при $1800 \mathrm{~K}$ в атмосфере кислорода при давлении $1 \cdot 10^{-6}$ Torr в течение $3 \mathrm{~h}$. Золото напылялось на ленту при $300 \mathrm{~K}$ из прямонакальной вольфрамовой трубки, в которую были помещены куски золотой фольги с чистотой $99.99 \%$, а калий напылялся на ленту также при $300 \mathrm{~K}$ из прямонакального испарителя путем термического разложения хроматов калия. Концентрация калия на поверхности ленты определялась по времени напыления постоянным потоком, интенсивность которого измерялась по току поверхностной ионизации на ленте, и составляла в монослое атомов калия $5 \cdot 10^{14}$ atom $/ \mathrm{cm}^{-2}$. Концентрация напыленного золота определялась по времени напыления и составляла в монослое атомов $\mathrm{Au} 1 \cdot 10^{15}$ atom $/ \mathrm{cm}^{-2}$. Температура образца с напыленными пленками калия и золота могла изменяться в диапазоне от 160 до $600 \mathrm{~K}$. Эксперимент был выполнен при температуре $300 \mathrm{~K}$. Детально эксперимент описан в работе [19].

\section{3. Результаты}

На рис. 1 показана зависимость выхода ЭСД $q\left(n_{\mathrm{K}}\right)$ атомов K с поверхности W, покрытого двумя монослоями $\mathrm{Au}$, при $T=300 \mathrm{~K}$ от поверхностной концентрации $\mathrm{K}$, адсорбированного на поверхности $\mathrm{Au} / \mathrm{W}$. При покрытиях калия, меньших одного монослоя, ЭСД атомов калия не наблюдается, что подтверждает общую картину формирования интерметаллидов при низких температурах: при покрытиях ЩМ, меньших одного монослоя, интерметаллид не образуется. Дальнейшая экспозиция образца в потоке калия приводит к появлению ЭСД атомов калия, что означает начало формирования неметаллического интеметаллида $\mathrm{K}_{x} \mathrm{Au}_{y}$. Наблюдается линейный рост выхода ЭСД атомов калия с увеличением количества напыленного К. При дозе напыления атомов калия, соответствующей двум монослоям К, наблюдается максимальное значение выхода ЭСД атомов калия. Дальнейшее же напыление атомов $\mathrm{K}$ не изменяет выход ЭСД. Можно предположить, что при напылении дозы

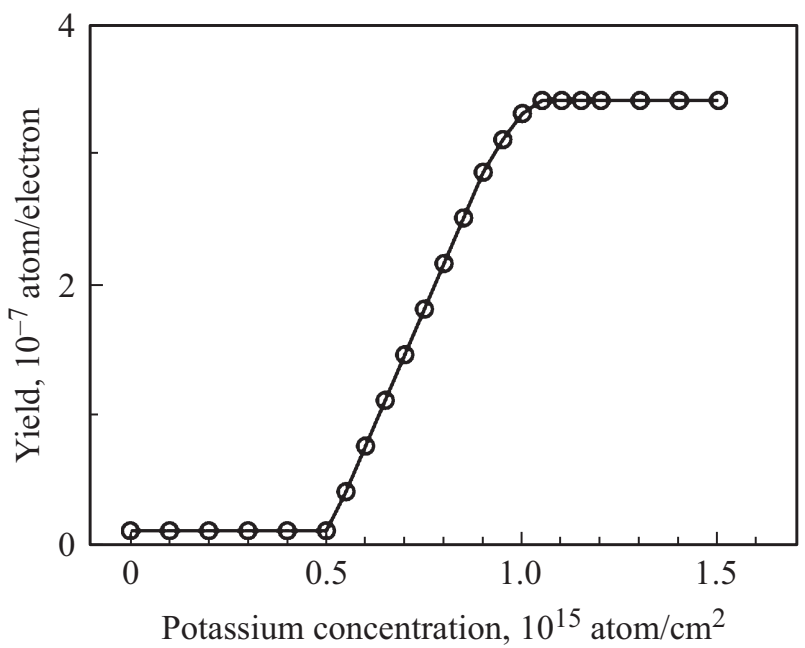

Рис. 1. Выход $q$ атомов К при ЭСД с вольфрама, покрытого двумя монослоями золота, при $T=300 \mathrm{~K}$ в зависимости от концентрации адсорбированного калия $n_{\mathrm{K}}$ для энергии бомбардирующих электронов $64 \mathrm{eV}$. 
в два монослоя $\mathrm{K}$ формируется полупроводниковое соединение $\mathrm{KAu}$, а при напылении дозы в три монослоя $\mathrm{K}$ можно ожидать формирования полупроводникового соединения $\mathrm{K}_{2} \mathrm{Au}$.

Похожая картина наблюдалась и при напылении атомов натрия или цезия на ультратонкую пленку золота на вольфраме [24]. Следует отметить, что формирование интерметаллидов $\mathrm{K}_{x} \mathrm{Au}_{y}$ не затрагивает поверхностный монослой атомов калия.

В следующем эксперименте было исследовано поведение выхода ЭСД атомов калия при фиксированной дозе напыленного K, но при изменении дозы напыленного золота. Доза напыления атомов калия соответствовала 1.0, 1.5 и 2.0 монослоя. Зависимости выхода ЭСД атомов К от времени напыления атомов $\mathrm{Au}$, a, следовательно, от покрытия атомами золота поверхности вольфрама представлены на рис. 2. Как и ожидалось напыление монослойной пленки калия на ультратонкую пленку золота толщиной, которая соответствует напылению от 0 до 5 монослоев золота, не приводит к регистрации ЭСД атомов калия. Это соответствует вышеприведенной схеме формирования соединений ЩМ-Au. В случае, когда доза напыленного калия 1.5 или 2.0 монослоя, ЭСД атомов калия начинает наблюдаться с формированием второго слоя золота. Зарегистрирован линейный рост выхода ЭСД атомов калия с увеличением покрытия Au. Максимум выхода ЭСД атомов калия достигается при напылении двух монослоев золота. Можно предположить, что происходит формирование соединений $\mathrm{KAu}_{2}$ при напылении 1.5 монослоя калия и $\mathrm{KAu}$ при напылении 2.0 монослоя $\mathrm{K}$ для пленки золота толщиной в два монослоя. Дальнейшее увеличение покрытия золота приводит к уменьшению выхода ЭСД атомов калия. Это уменьшение выхода может быть вызвано возможным

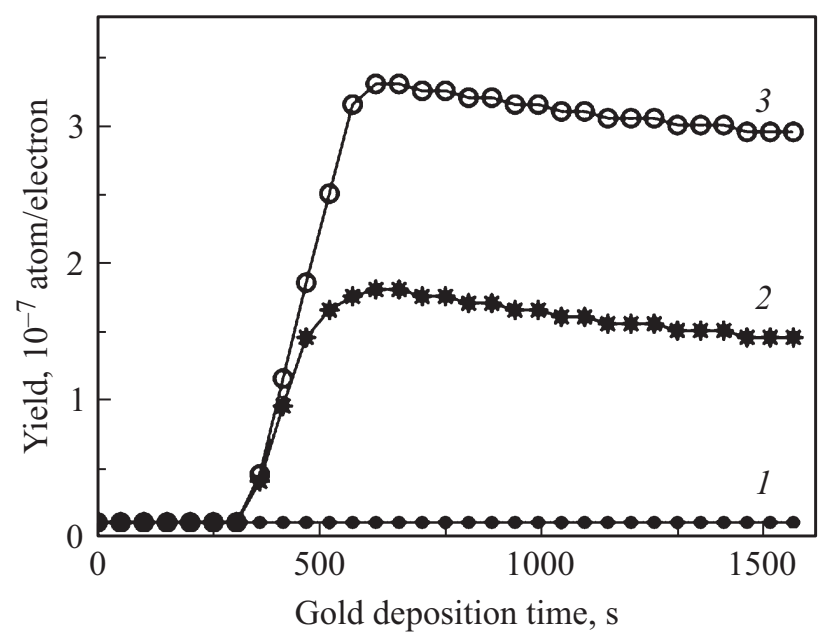

Рис. 2. Выход $q$ атомов $\mathrm{K}$ при ЭСД с вольфрама, покрытого золотом, при $T=300 \mathrm{~K}$ в зависимости от времени напыления золота для трех концентраций калия $n_{\mathrm{K}}: 1-0.50 \cdot 10^{15}$ atom $/ \mathrm{cm}^{2}, 2-0.75 \cdot 10^{15}$ atom $/ \mathrm{cm}^{2}$, $3-1.0 \cdot 10^{15}$ atom $/ \mathrm{cm}^{2}$. Энергия бомбардирующих электронов $64 \mathrm{eV}$.

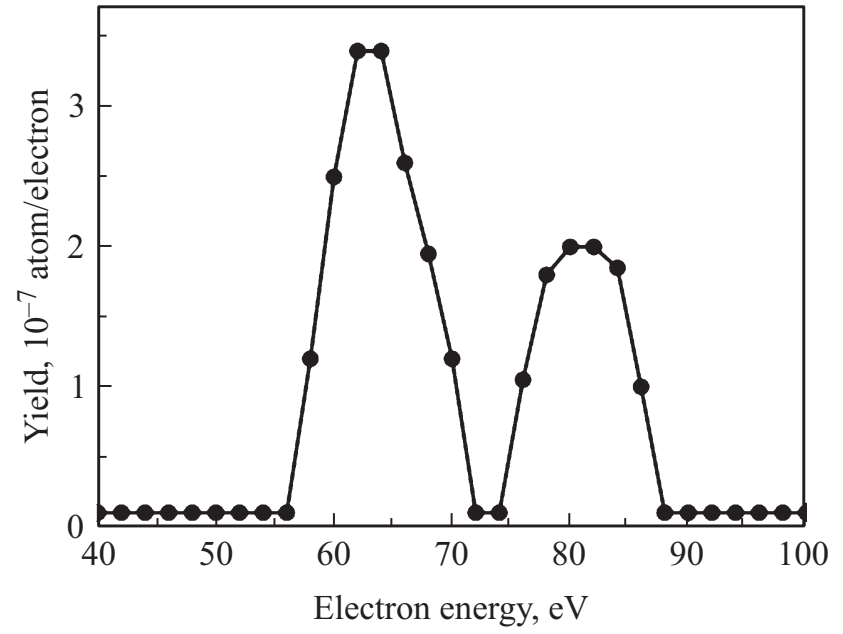

Рис. 3. Выход $q$ атомов К при ЭСД с вольфрама, покрытого двумя монослоями золота и двумя монослоями калия, при $T=300 \mathrm{~K}$ в зависимости от энергии бомбардирующих электронов $E_{e}$.

формированием наночастиц $\mathrm{Au}$ на поверхности W ранее было обнаружено формирование нанокристаллитов при напылении на вольфрам золотых покрытий толщиной несколько монослоев [28]. Образование наночастиц $\mathrm{Au}$ приводит к уменьшению облучаемой площади поверхности, так как угол падения возбуждающих ЭСД электронов на поверхность составляет 45 градусов.

Энергетическая зависимость $q\left(E_{e}\right)$ выхода ЭСД атомов $\mathrm{K}$ от энергии возбуждающих электронов $\left(E_{e}\right)$ приведена на рис. 3. Наблюдается квазирезонансная зависимость $q$ выхода ЭСД атомов К от энергии возбуждающих электронов с поверхности W, покрытого двумя монослоями Аu для напыленного при $T=300 \mathrm{~K}$ калия. Видны два хорошо разрешенных пика выхода с максимумами при 64 и $82 \mathrm{eV}$. Эти пики связываются с возбуждением облучающими электронами остовных уровней $\mathrm{Au} 5 p_{3 / 2}$ и $\mathrm{Au} 5 p_{1 / 2}$. Отношение площадей под пиками $1: 1.7$, что немного меньше ожидаемого спинорбитального отношения $1: 2$. Пики хорошо описываются гауссианами с полной шириной на полувысоте 8.9 и $8.6 \mathrm{eV}$ для пиков при 64 и $82 \mathrm{eV}$, соответственно.

На рис. 4 представлены нормированные энергораспределения (ЭР) атомов калия с поверхности вольфрама, покрытого двумя монослоями золота и напыленного при $300 \mathrm{~K}$ калия, для двух энергий возбуждения ЭСД атомов калия: 82 и $64 \mathrm{eV}$, которые соответствуют двум пикам в энергетической зависимости выхода ЭСД атомов калия. Оба пика в ЭР практически совпадают и имеют полную ширину на полувысоте $0.1 \mathrm{eV}$. Отметим, что в экспериментах, выполненных при $300 \mathrm{~K}$, для ЭСД атомов натрия [29] и цезия [30] с поверхности ЩМАи в ЭР наблюдаются два узких пика в случае натрия и один пик в случае цезия. Ширина на полувысоте для цезиевого пика составляла $0.11 \mathrm{eV}$, а для натриевого пика, расположенного при больших кинетических энергиях, $0.81 \mathrm{eV}$. 


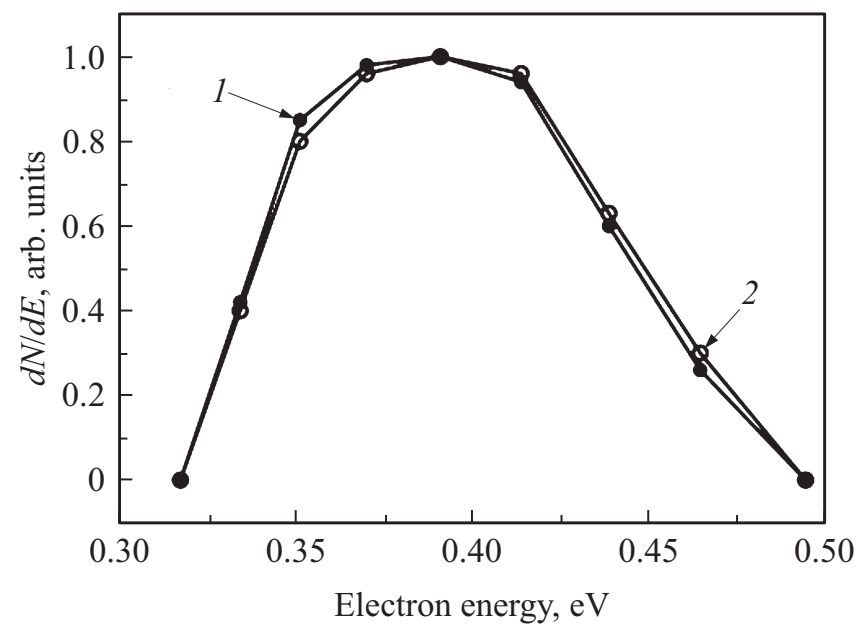

Рис. 4. Нормированные энергораспределения десорбирующихся атомов калия с поверхности вольфрама, покрытого двумя монослоями золота и двумя монослоями калия, при $T=300 \mathrm{~K}$ для двух энергий возбуждения ЭСД атомов калия: $1-82 \mathrm{eV}$ и $2-64 \mathrm{eV}$.

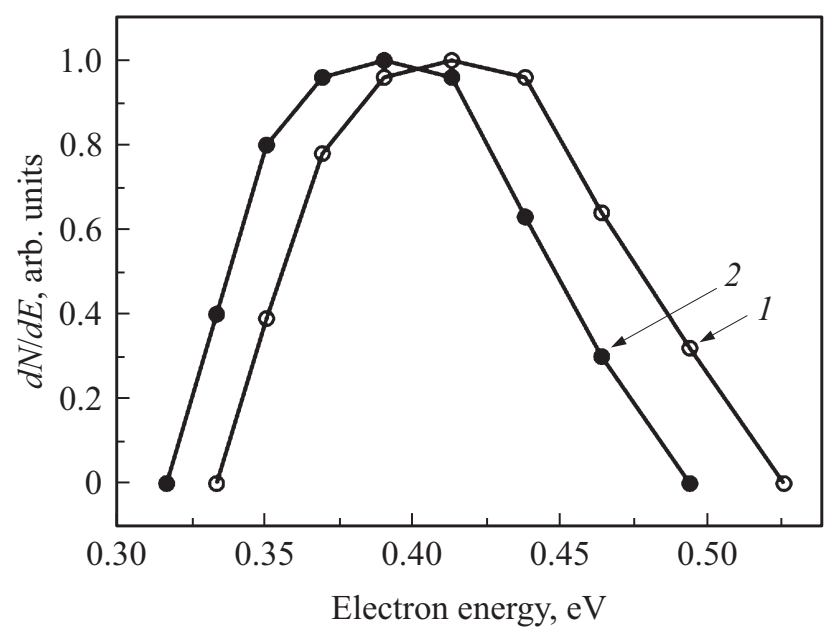

Рис. 5. Нормированные энергораспределения десорбирующихся атомов калия с поверхности вольфрама, покрытого двумя монослоями золота, при $T=300 \mathrm{~K}$ для энергии возбуждения ЭСД атомов калия $64 \mathrm{eV}$ и для двух доз напыления калия: $1-1.5$ монослоя, $2-2.0$ монослоя.

Как видно, атомы калия по своему поведению являются как бы промежуточным вариантом между атомами цезия и атомами натрия, что подтверждает сдвиг максимума в ЭР от натрия к цезию: максимумы расположены при $0.34,0.39$ и $0.45 \mathrm{eV}$ для $\mathrm{Na}, \mathrm{K}$ и $\mathrm{Cs}$ соответственно. Наличие одного максимума в ЭР атомов калия при ЭСД означает наличие только одного канала ЭСД в поверхностном монослое атомов калия.

Увеличение калиевого покрытия с 1.5 монослоя до 2.0 монослоя приводит, во-первых, к уменьшению ширины пика на полувысоте с 0.11 до $0.10 \mathrm{eV}$, так и к сдвигу максимума в сторону меньших энергий с 0.42 до $0.39 \mathrm{eV}$ (рис. 5). Похожая картина была обнаружена ранее для
ЭСД атомов натрия [29] и цезия [30] с поверхности ЩМАи. Наличие сдвига в сторону меньших энергий в ЭР с ростом калиевого покрытия можно связать с увеличением расстояния между адсорбированным атомом калия и слоем $\mathrm{K}_{x} \mathrm{Au}_{y}$.

\section{4. Обсуждение результатов}

Для объяснения процесса электронно-стимулированной десорбции атомов $\mathrm{K}$ в системе $\mathrm{K} / \mathrm{K}_{x} \mathrm{Au}_{y} / \mathrm{Au} / \mathrm{W}$ на вольфраме воспользуемся идеями, предложенными ранее в [19]. Наличие только одного канала возбуждения процесса ЭСД существенно упрощает картину от ситуации, когда в процессе ЭСД задействованы два канала, как в случае $\mathrm{Cs} / \mathrm{CsAu} / \mathrm{Au} / \mathrm{W}$ при низких температурах [19]. Наблюдаемая нами ЭСД атомов калия с поверхности $\mathrm{K} / \mathrm{K}_{x} \mathrm{Au}_{y} / \mathrm{Au} / \mathrm{W}$ означает, что сформировавшийся слой $\mathrm{K}_{x} \mathrm{Au}_{y}$ имеет неметаллический характер, т. е. сформированный слой $\mathrm{K}_{x} \mathrm{Au}_{y}$ можно считать 2D-полупроводником на металлической подложке. То, что данное соединение является полупроводником, не совпадает с результатами расчетов электронной структуры $\mathrm{KAu}[31,32]$. Полученное расхождение можно объяснить тем, что производился расчет объемного инетерметаллида со стехиометрией $\mathrm{KAu}$, однако, как видно из наших результатов, возможно образование соединений $\mathrm{K}_{x} \mathrm{Au}_{y}$ с различным соотношением $x: y$, а полученная в

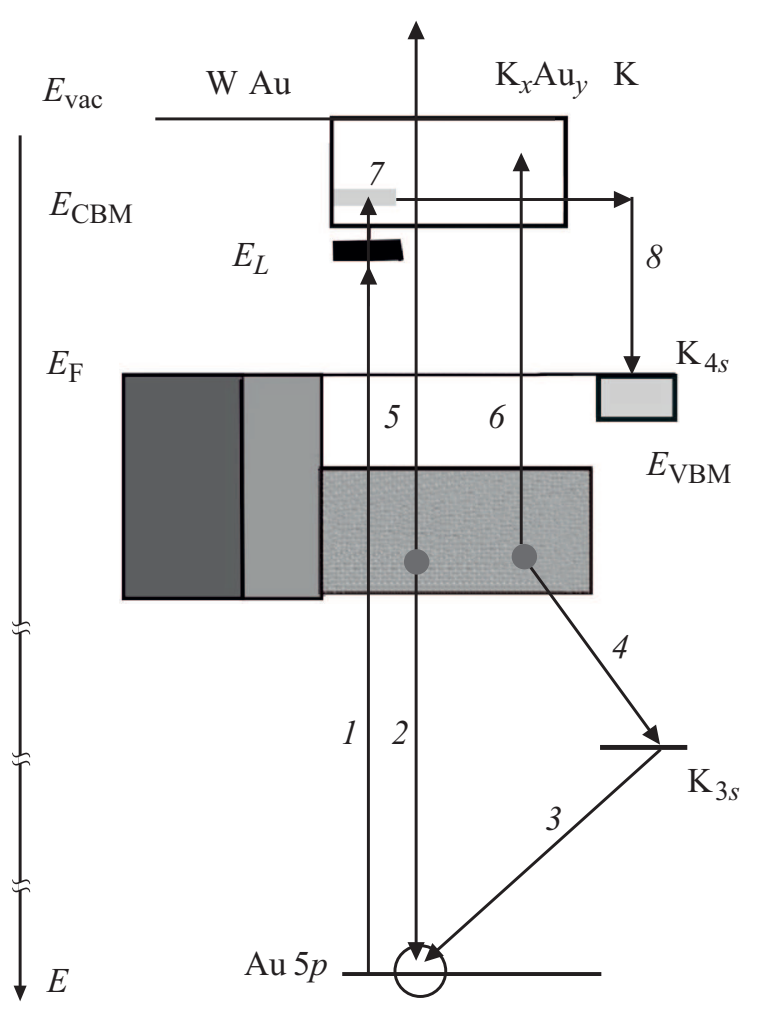

Рис. 6. Схема процессов ЭСД в системе слой $\mathrm{K} /$ слой $\mathrm{KAu} /$ монослой $\mathrm{Au} /$ подложка W. $E_{\mathrm{VBM}}$ - энергия, соответствующая максимуму валентной зоны. $E_{\mathrm{F}}-$ уровень Ферми. 
наших экспериментах пленка не превышает нескольких атомных слоев.

На рис. 6 приведена схема процессов, происходящих в электронной структуре системы $\mathrm{K} / \mathrm{K}_{x} \mathrm{Au}_{y} / \mathrm{Au} / \mathrm{W}$. Электронное облучение образца приводит к возбуждению электрона с остовного уровня $\mathrm{Au} 5 p(1)$ в локальное состояние $E_{L}$ рядом с дном зоны проводимости $E_{\mathrm{CBM}}$, опустившееся из зоны проводимости в поле образовавшейся остовной дырки $\mathrm{Au} 5 p^{+}$в запрещенную зону полупроводника $\mathrm{K}_{x} \mathrm{Au}_{y}$. Именно возбуждение электрона из $\mathrm{Au} 5 p$-состояний электронным облучением системы в зону проводимости приводит к образованию „квазирезонансного“ пика на рис. 3. Нейтрализация дырки $\mathrm{Au} 5 p^{+}$ возможна за счет переходов электронов из валентной зоны интерметаллида (2) или с уровня $\mathrm{K} 5 s$ (3), которую сопровождают Оже-процессы, включающие в себя заполнение всех дырок, возникших в электронной структуре образца, и возбуждение электронов валентной зоны в вакуум (5) или в зону проводимости (6) за счет выделяющейся энергии. Так как локальное состояние расположено вблизи $E_{\mathrm{CBM}}$ (для системы $\mathrm{Cs} / \mathrm{CsAu}$ оно расположено ниже на $50 \mathrm{meV}$ [19]), то электрон может быть легко захвачен в зону проводимости (7). Электрон из зоны проводимости захватывается адсорбированным атомом $\mathrm{K}(8)$ с образованием нейтрального атома $\mathrm{K}^{0}$ в монослое К. Образованный при этом атом $\mathrm{K}^{0}$ увеличивается в объеме и выталкивается из монослоя К на поверхности. Следует отметить, что в процессы ЭСД атомов К связаны с электронными переходами в области интерфейса адсорбированный слой атомов $\mathrm{K}$ ближайший к нему слой $\mathrm{K}_{x} \mathrm{Au}_{y}$.

\section{5. Заключение}

Обнаружена электронно-стимулированная десорбция атомов $\mathrm{K}$ в системе $\mathrm{K} / \mathrm{K}_{x} \mathrm{Au}_{y}$ при температуре $300 \mathrm{~K}$. Наблюдается квазирезонансная зависимость выхода ЭСД атомов К от энергии возбуждающих электронов, связанная с возбуждением остовных уровней $\mathrm{Au} 5 p_{3 / 2}$ и $\mathrm{Au} 5 p_{1 / 2}$. Наблюдается только один пик в энергораспредлении десорбирующихся атомов калия в процессе ЭСД, что указывает на единственный канал ЭСД десорбция атомов калия происходит из поверхностного монослоя атомов калия. Показано, что энергетические характеристики десорбирующихся атомов калия занимают промежуточное положение между энергетическими характеристиками десорбирующихся атомов натрия и цезия. Можно предположить формирование $\mathrm{KAu} \mathrm{в}$ случае напыления двух монослоев золота с дальнейшей трансформацией в $\mathrm{K}_{2} \mathrm{Au}$ с увеличением количества напыленного К. Предложена модель процессов, происходящих в системе $\mathrm{K} / \mathrm{K}_{x} \mathrm{Au}_{y} / \mathrm{Au} / \mathrm{W}$. Процесс ЭСД захватывает атомы, расположенные в адсорбированном слое атомов $\mathrm{K}$ и ближайшем к нему слое $\mathrm{KAu}_{y}$.

\section{Финансирование работы}

Исследование выполнено при финансовой поддержке РФФИ в рамках научного проекта № 20-02-00370.

\section{Конфликт интересов}

Авторы заявляют, что у них нет конфликта интересов.

\section{Список литературы}

[1] W.E. Spicer, A.N. Sommer, J.G. White. Phys. Rev. 115, 57 (1959).

[2] М.В. Кнатько, М.Н. Лапушкин, В.И. Палеев. ЖТФ 68, 108 (1998).

[3] M. Jansen. Chem. Soc. Rev. 37, 1826 (2008).

[4] P. Priecelm, H.A. Salami, R.H. Padilla, Z.Z.J.A. LopezSanchez. Chin. J. Catalysis 37, 1619 (2016).

[5] L.X. Dien, T. Ishida, A. Taketoshi, D.Q. Truongd, H.D. Chinh, T. Honm, T. Murayama, M Haruta. Appl. Catalysis B 241, 539 (2019).

[6] P.G. Jamkhande, N.W. Ghule, A.H. Bamer, M.G. Kalaskar. J. Drug Delivery Sci. Techn. 53, 101174 (2019).

[7] Y. Kumari, G. Kaur, R. Kumar, S.K. Singh, M. Gulati, R. Khursheed, A. Clarisse, K. Gowthamarajan, V.V.S. Narayana, R. Karri, R.M.D. Ghosh, A. Awasthi, R. Kumar, A. Kumar, B.K.P.K. Singh, K. Dua, O. Porwal. Adv. Colloid Interf. Sci. 274, 102037 (2019).

[8] M.A. Xiao-Ming, S. Mi, L. Yue, L. Yin-Jin, L. Fang, G. LongHua, Q. Bin, L. Zhen-Yu, C. Guo-Nan. Chin. J. Anal. Chem. 46, 1 (2018).

[9] G. Korotcenkov, V. Brinzari, B.K. Cho. Microchim. Acta 183, 1033 (2016).

[10] J.A. Rodriguez, D.C. Grinter, P.J. Ramírez, D.J. Stacchiola, S. Senanayake. J. Phys. Chem. C 122, 4324 (2018).

[11] M. Ayyoob, M.S. Hegde. J. Chem. Soc. Faraday Trans. 86, 1893 (1990).

[12] A.M. Kiss, M. Svec, A. Berko. Surf. Sci. 600, 3352 (2006).

[13] R. Pang, H. Qina, Z. Cai, M. Liu, S. Chen, J. Zhong, D. Zhong. Surf. Sci. 684, 18 (2019).

[14] A. Neumann, S.L.M. Schroeder, K. Christmann. Phys. Rev. B 51, 17007 (1995).

[15] S.L.M. Schroeder, A. Neumann, T. Solomun, P. LenzSolomun, K. Christmann. Surf. Sci. 337, 285 (1995).

[16] T.Y.B. Leung, D.P. Butcher, A.A. Gewirth. J. Phys. Chem. C 116, 555 (2012).

[17] М.В. Кнатько, М.Н. Лапушкин, В.И. Палеев. ЖТФ 68, 108 (1998).

[18] M.V. Knatko, M.N. Lapushkin, V.I. Paleev. Phys. LowDimens. Struct. 9/10, 57 (2001).

[19] Ю.А. Кузнецов, М.Н. Лапушкин, Н.Д. Потехина. Письма в ЖТФ 42, 14 (2016).

[20] Д.П. Бернацкий, В.Г. Павлов. ФТТ 46, 1494 (2004).

[21] M.V. Knatko, M.L. Lapushkin, V.I. Paleev. Phys. Low Dimens. Struct. 9/10, 85 (1999).

[22] M. Miao, J. Brgoch, A. Krishnapriyan, A. Goldman, J.A. Kurzman, R. Seshadri. Inorg. Chem. 52, 8183 (2013). 
[23] G. Kienast, J. Verma, W. Klemm. Z. Anorg. Allgem. Chem. 310, 143 (1961).

[24] В.Н. Агеев, Е.Ю. Афанасьева. ФТТ 48, 2217 (2006).

[25] В.Н. Агеев, Ю.А. Кузнецов, Н.Д. Потехина. ФТТ 50, 1524 (2008).

[26] V.N. Ageev. Prog. Surf. Sci. 47, 55 (1994).

[27] T.E. Madey. Surf. Sci. 299/300, 824 (1994).

[28] E. Bauer, H. Poppa, G. Todd, P.R. Davis. J. Appl. Phys. 48, 3773 (1977).

[29] В.Н. Агеев, Ю.А. Кузнецов. ФТТ 50, 365 (2008).

[30] В.Н. Агеев, Ю.А. Кузнецов, Н.Д. Потехина. ЖТФ 83, 85 (2013).

[31] R.E. Watson, M. Weinert. Phys. Rev. B 49, 7148 (1994).

[32] C. Koenig, N.E. Christensen, J. Kollar. Phys. Rev. B 29, 6481 (1984).

Редактор Д.В. Жуманов 